\title{
Application of BMP to urban runoff control using SUSTAIN model: Case study in an industrial area
}

\author{
Jie Gao ${ }^{\mathrm{a}}$, Rusong Wang ${ }^{\mathrm{a}}$, Jinlou Huang ${ }^{\mathrm{a}, *}$, Min Liu ${ }^{\mathrm{b}}$ \\ a State Key Laboratory of Urban and Regional Ecology, Research Center for Eco-Environmental Sciences, Chinese Academy of Sciences, Beijing 100085, China \\ ${ }^{\mathrm{b}}$ Hainan Research Academy of Environmental Sciences, Haikou 571126, China
}

\section{A R T I C L E I N F O}

\section{Article history:}

Available online 14 July 2015

\section{Keywords:}

Stormwater management

Best management practices

SUSTAIN model

Optimization

Ecosystem services

\begin{abstract}
A B S T R A C T
Flooding and stormwater pollution by urban runoff owing to the effects of urbanization and industrialization on both hydrology and water quality have become a serious issue. Best management practices (BMP) are proposed to mitigate floods and reduce pollutants, the performance of which can be quantitatively assessed by the System for Urban Stormwater Treatment and Analysis Integration (SUSTAIN) model. A factory in the city of Ma'anshan, China was selected as a case study for planning and analysis of BMP. First, surface runoff pollution was identified as being caused by different land uses at this site. BMP such as permeable pavements, vegetated swales, green roofs, wet ponds, and bioretention basins were planned for this site. After BMP planning, system performance was evaluated using SUSTAIN. Sizes of the implemented BMP were further adjusted using the optimization module of SUSTAIN. Quantitative analyses of pollutant purification and flood mitigation ecosystem services after optimization were conducted. The results indicate that pollution caused by urban surface runoff in the study area was serious and required treatment. Compared with the developed condition, the BMP plan would reduce total runoff volume, total suspended solid load, dissolved zinc load, total nitrogen load, total phosphorus load and chemical oxygen demand load by $41 \%, 62 \%, 55 \%, 57 \%, 55 \%$ and $60 \%$, respectively. This research result is of practical importance for urban nonpoint source pollution caused by industrial activities.
\end{abstract}

(c) 2015 Elsevier B.V. All rights reserved.

\section{Introduction}

Large areas of natural green lands have been occupied by buildings during the rapid urbanization process, leading to a sharp rise of impervious land in urban areas (Brown and Peake, 2006). Stormwater runoff from urban areas carries various pollutants to receiving waters, resulting in significant water quality problems. In recent years, urban nonpoint source pollution has gradually become the major pollution source in water quality deterioration (Davis and Birch, 2009; Lee and Bang, 2000). There has been a number of studies on urban nonpoint source pollution for many cities throughout China (e.g., Che et al., 2003; Li et al., 2007; Ren et al., 2008), arousing widespread concern among scientists, environmentalists, government regulators, and the public in China. Currently, research of urban nonpoint source pollution focused on various land uses, including typical residential, commercial, industrial, road and roof areas (Clark et al., 2008; Lee et al., 2002; Luo et al., 2012), of which very few is concerning those close to factories. The characteristics of

\footnotetext{
* Corresponding author. Tel.: +86 1062849147; fax: +86 1062849147

E-mail address: jlhuang@rcees.ac.cn (J. Huang).
}

pollution in industrial areas are different from those in residential and commercial areas. The research result showed that event mean concentrations (EMCs) for residential area was generally higher than that of industrial area (Lee and Bang, 2000; Lee et al., 2002).

The traditional urban drainage system is mainly a singleobjective oriented design with a focus on water quantity control, which overlooks other important aspects such as runoff quality, recreational value and ecological protection. Researchers in developed countries have explored a series of systematic urban stormwater control technologies, such as best management practices (BMP) (EPA, 1999), sustainable urban drainage systems (Napier et al., 2009), and water sensitive urban design (Coombes et al., 1999). BMP is the most representative implementation of sustainable drainage and have been widely used in the USA (Arcy and Frost, 2001). There is extensive literature on the ecological benefits of BMP for stormwater management, such as the use of green roofs (Czemiel Berndtsson, 2010; Vijayaraghavan et al., 2012), vegetated filter strips (Abu-Zreig et al., 2004), bioretention (Kim et al., 2012), and porous pavement (Scholz and Grabowiecki, 2007). Literature on the design and optimization of BMP has been reviewed. Zhen et al. (2004) presented a method that coupled an agricultural nonpoint source pollution model and scatter search for optimizing 
the placement and configuration of BMP at watershed scale. PerezPedini et al. (2005) described a distributed hydrologic model combined with a genetic algorithm to determine the optimal location of infiltration-based BMP. Zhang (2006) used a revised version of the non-dominated sorted genetic algorithm-II (NSGA-II) and epsilon non-dominated sorted genetic algorithm to optimize various low impact development designs in an urbanizing watershed. Oraei Zare et al. (2012) studied technologies that coupled the storm water management model (SWMM) with NSGA-II to control both the quality and quantity of urban floods.

A comprehensive modeling system is necessary to systematically evaluate the location, type, and cost of stormwater BMP. Two stormwater management systems have been developed, i.e., Best Management Practice Decision Support System (BMPDSS) and System for Urban Stormwater Treatment and Analysis Integration (SUSTAIN). BMPDSS has been used in the Beijing Olympic Village (Jia et al., 2012) and for a highway in Prince George's County in the United States (Cheng et al., 2009) to implement BMP for urban runoff control. The US Environmental Protection Agency developed SUSTAIN to provide stormwater managers with a decision support system for cost-efficient selection and placement of BMP in urban watersheds (EPA, 2009). A case study in Kansas City, MO, USA explored the use of SUSTAIN to evaluate green infrastructure management alternatives for the mitigation of combined sewer overflows (Lee et al., 2012).

The goal of the present study is to determine the optimal number and location of BMP in an industrial plant to reduce runoff volume and pollutant loading at the outlet of the study area. Combined with multiple, distinct models that include algorithms for simulating urban hydrology, pollutant loading, and treatment processes, SUSTAIN aids the development, evaluation, selection, and placement of BMP options based on cost and effectiveness. Therefore, we aimed to find the most cost-effective selection, design, and placement of BMP as determined by SUSTAIN.

Green space and water space can provide ecosystem services, such as pollutant purification, flood mitigation, and others (Niemelä et al., 2010). Some BMP facilities, such as vegetated swale, wet and dry ponds, are transformed green space and water space. After transformation, green and water spaces are more effective in mitigating floods and reducing pollutants. In this research, quantitative analysis of pollutant purification and flood mitigation ecosystem services provided by green and water spaces is conducted under various combinations of BMP.

\section{Model description}

SUSTAIN (version 1.2) (EPA, 2009) is a decision-support system to assist with stormwater management study, planning, and design. The system is a public-domain tool capable of evaluating the optimal location, type, and cost of stormwater BMP that are required to meet water quality goals. Tested algorithms from SWMM, Hydrological Simulation Program - Fortran (HSPF), and other BMP modeling techniques were packaged together in SUSTAIN. The SUSTAIN model is built on a base platform interface using ArcGIS, which provides the user access to framework components, which are a BMP sitting tool, watershed runoff and routing module, BMP simulation module, BMP cost analysis module, optimization module, and post-processor. Fig. 1 shows the relationships between the land, BMP, conveyance and optimization modules to assess BMP in SUSTAIN. The figure also shows inputs and methods used to simulate water quality processes.

Four types of data were used: (1) physiographic and hydrometeorological data, including land use, digital elevation, stream network, weather, and precipitation; (2) hydraulic data, including channel network and dimension, roughness coefficient, and required elevations; (3) quality data for build-up and wash-off model simulations; and (4) cost of the BMP.

\section{Case study}

\subsection{Study area description}

A factory plant within an economic zone was selected as a case study site in Ma'anshan, Anhui Province, China $\left(31^{\circ} 35^{\prime} 48.97^{\prime \prime} \mathrm{N}\right.$, $118^{\circ} 28^{\prime} 37.04^{\prime \prime} \mathrm{W}$ ) (Fig. 2). Average annual rainfall is $1100 \mathrm{~mm}, 48 \%$ of which occurs from June through August. The site covers 13.3 ha and consists of an employee dormitory, workshop, and auxiliary facilities. Land uses include buildings (27.4\%), green space (24.5\%), impervious roads (35.1\%), and water space (13\%) (Fig. 3). A separate sewer system for runoff was not built, so runoff from the site was discharged directly into a water body, impairing water quality.

To identify surface runoff pollution caused by various land uses at the site, stormwater runoff samples were collected according to land use type (building roof, impervious road, and green space). Runoff samples were collected manually using 5-L polyethylene buckets at 5-min intervals during each event. The EMC approach was used to quantify pollution of the runoff. Rainfall events were

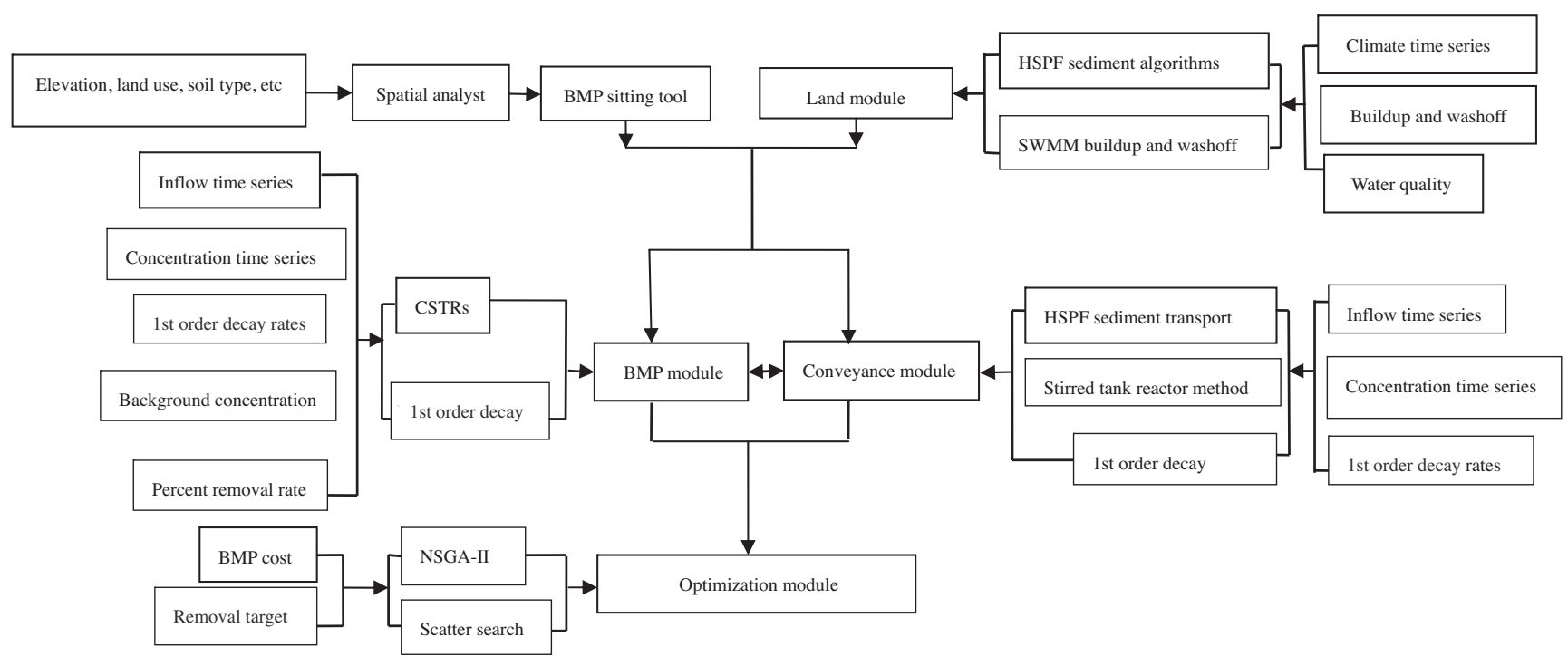

Fig. 1. Simulation process of assessing BMP in SUSTAIN model. 


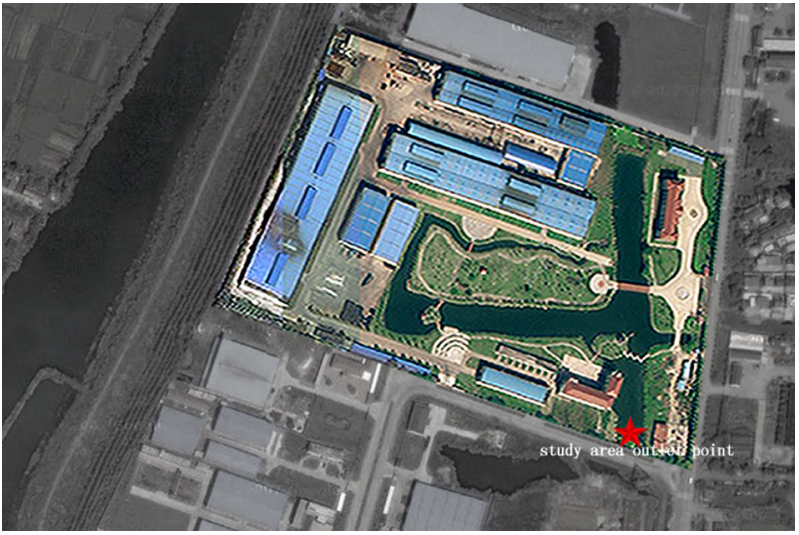

Fig. 2. Aerial photo and runoff exit location of the study site.

monitored from July to October 2011. Concentrations of total suspended solids, chemical oxygen demand (COD), total nitrogen (TN), total phosphorus (TP), and dissolved zinc ( $\mathrm{Zn})$ in runoff samples were analyzed within $24 \mathrm{~h}$, according to methods described by the State Environmental Protection Administration of China.

EMCs of various pollutants in surface runoff are shown in Table 1. The data reveal that COD, TN and TP values significantly exceeded the Class V surface water quality standard (GB3838-2002) developed by the Ministry of Environmental Protection (MEP) of the People's Republic of China. EMCs of various pollutants varied from typical values observed in similar urban areas of China (Beijing, Wuhan, Shanghai, and Chongqing) and cities abroad, according to other studies in the literature (Ballo et al., 2009; Che et al., 2003; Gromaire-Mertz et al., 1999; Li et al., 2007; Ren et al., 2008; Wang et al., 2013). For road runoff, EMCs of COD and TSS in the present study were 2-3 times higher than those in Beijing, Paris, and a German city. For roof runoff, EMCs of TSS, COD and TP were all higher than those in Beijing. The results indicate that pollution caused by urban surface runoff in the study area was serious and required treatment.
Table 1

EMC values of pollutants in runoff samples collected from different land use areas.

\begin{tabular}{llllll}
\hline Land use & TSS $(\mathrm{mg} / \mathrm{l})$ & $\mathrm{COD}(\mathrm{mg} / \mathrm{l})$ & $\mathrm{TN}(\mathrm{mg} / \mathrm{l})$ & $\mathrm{TP}(\mathrm{mg} / \mathrm{l})$ & $\mathrm{Zn}(\mathrm{mg} / \mathrm{l})$ \\
\hline Road & 456.5 & 354.9 & 30.18 & 3.50 & 0.22 \\
Roof & 91.5 & 189 & 14.30 & 0.02 & 0.08 \\
Green space & 50.5 & 166.5 & 14.33 & 0.26 & 0.09 \\
\hline
\end{tabular}

\subsection{BMP planning}

BMP types, sizes, and spatial layouts should be determined in accord with local conditions (elevation, slope, soil type, urban land use, roads, water table depth, stream location, and drainage area). After analyzing the above conditions, potential areas of BMP implementation were determined for the case study site, as described below. The parkinglot and impervious road, both far from the workshop, could be retrofitted to implement permeable pavement, and existing green space along the road could be transformed to vegetated swales. The building roof could be retrofitted to implement a green roof, and existing water space could be converted to a wet pond. Pervious areas, such as a green space near a building, could be converted to bioretention basins. Fig. 4 shows locations for BMP implementation.

\subsection{BMP assessment}

After BMP planning, system performance was evaluated using algorithms from the land, BMP and conveyance modules of SUSTAIN. Target indices were annual average flow volume (AAFV) and annual average load (AAL) for TSS, COD, TN, TP and $\mathrm{Zn}$. Rainfall data used in the analysis were from 2011, which was considered a typical year for the Ma'anshan area in terms of total rainfall its seasonal distribution. Hydraulic (Arnold et al., 1998; Soulis and Valiantzas, 2011, 2012) and quality (Goonetilleke et al., 2009; Hossain et al., 2011; Kim et al., 2006; Wang and Li, 2009) data were taken from similar research in literature.

For comparison, three scenarios were set in SUSTAIN: Predevelopment (PreDev), Post-Development (PostDev), and Developed with BMP (Existing).

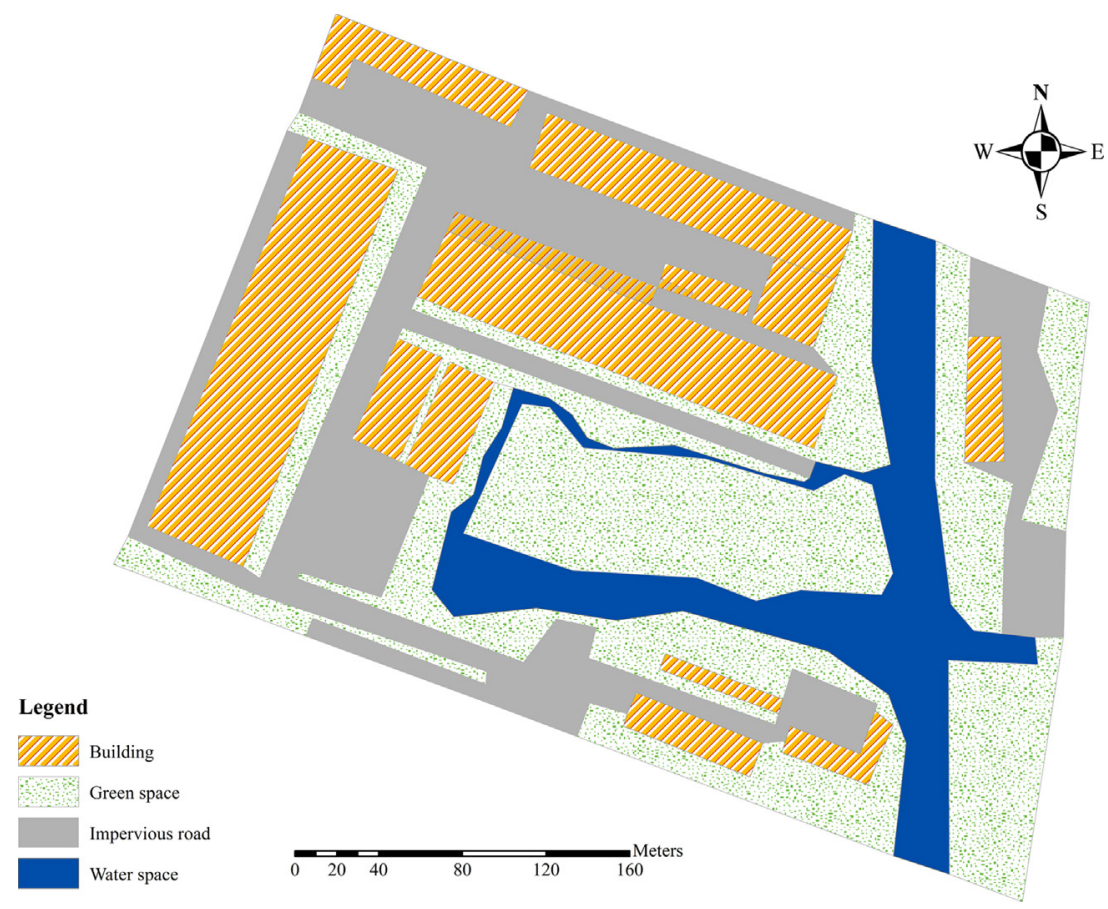

Fig. 3. Land use map of the study site. 


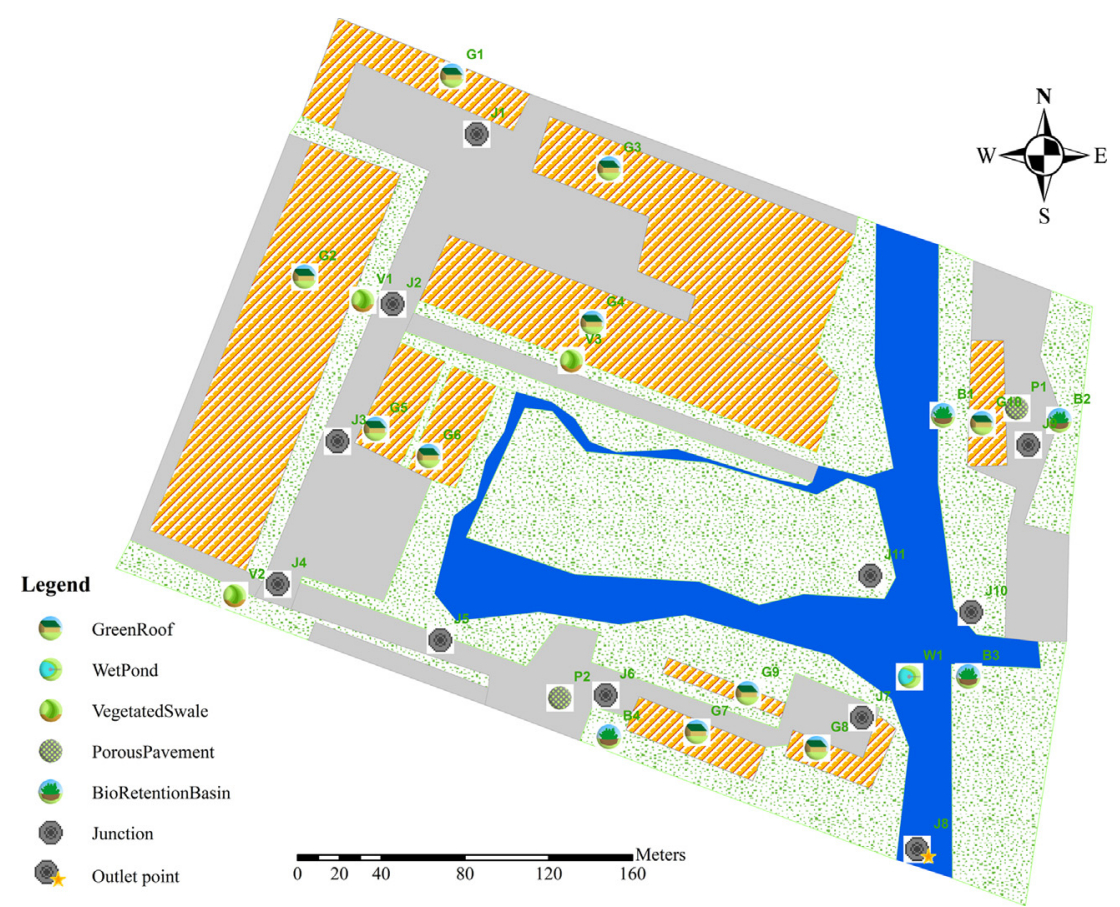

Fig. 4. BMP locations and types at the study site.

(1) Pre-Development was the condition prior to development. This was represented using the land-use timeseries specified as "pre-development land-use type"; the site land use type is green space.

(2) Post-Development was a developed condition without any BMP. This site was developed as a factory with no BMP facilities. Runoff was generated from the road and roof. Therefore, the flow volume and pollutant load under this scenario was evaluated in the land module using the hydraulic and water quality parameters of roof and road runoff.

(3) Developed with BMP was a developed condition with any existing BMP. This would be identical to the post-development condition if there were no existing BMP. BMP facilities such as green roofs, vegetated swales, wet ponds, bioretention basins and permeable pavements have been planned at this site according to BMP design principles, which consider elevation, slope, land use, and other factors. The flow volume and pollutant load under this scenario were evaluated in the BMP module with inputs background concentrations, dimensions, pollutant removal, and substrate properties of BMP.

Figs. 5 and 6 show evaluation results under various scenarios. Under the PostDev scenario, AAFV and AAL of Zn, TN, TP, TSS and COD increased 5, 20, 11, 10, 24 and 21 times, respectively, compared with corresponding quantities under the PreDev scenario.

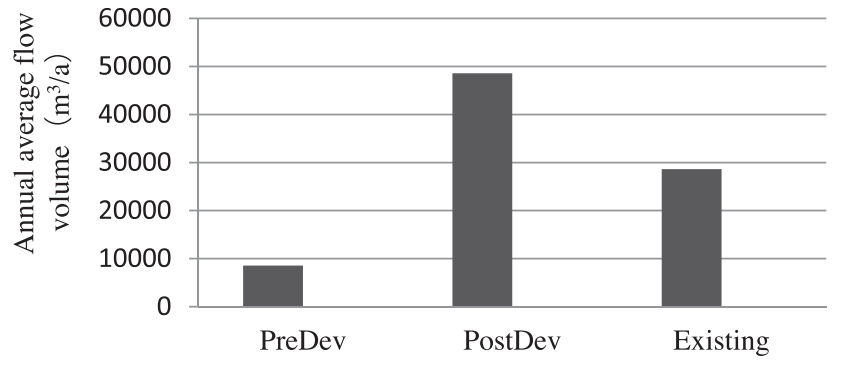

Fig. 5. Runoff volume under various scenarios.
For AAFV, under the Existing scenario, 41\% more volume reduction would be achieved compared with that under the PostDev scenario. For AAL of TSS, Zn, TN, TP and COD under the Existing scenario, $62 \%, 55 \%, 57 \%, 55 \%$ and $60 \%$ greater load reductions would be achieved, respectively, compared with those under the PostDev scenario. These results indicate that runoff volume and pollutant loads were significantly reduced by properly planning the BMP at the study site.

\subsection{BMP optimization}

To demonstrate whether BMP designs could be revised for better performance or reducing costs, we evaluated a large number of diverse BMP scenarios using the optimization module process, and compared cost and BMP effectiveness against user-defined targets to determine the most cost-effective BMP solutions. To perform the optimization, SUSTAIN requires the user to specify decision variables, evaluation factors, management targets, assessment points, and costs of the BMP. The decision variables and their ranges are summarized in Table 2. The assessment point was the outlet of the study site (Fig. 2). The cost of each BMP facility was estimated according to information collected from the local market prices.

Two optimization targets were set for the analysis, as follows:

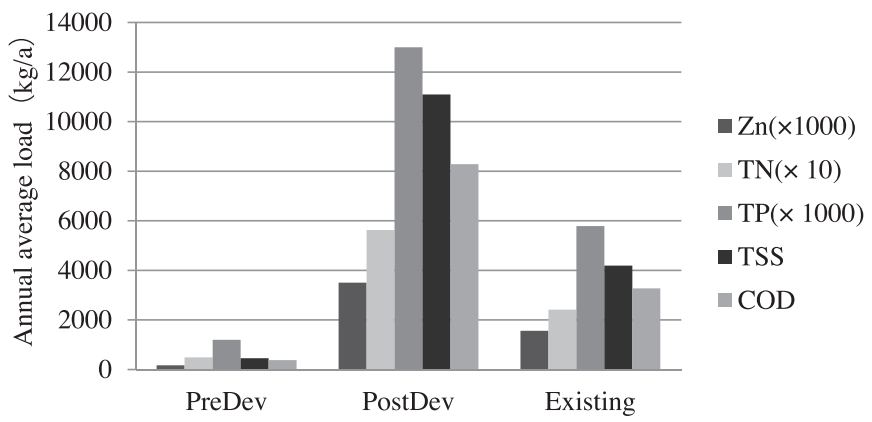

Fig. 6. Pollutant loads under various scenarios. 
Table 2

BMP optimization decision variables.

\begin{tabular}{|c|c|c|c|c|c|c|c|c|c|}
\hline Sub-watershed & BMP ID & Decision variable & Min & Max & Search interval & Decision variable & Min & Max & $\begin{array}{l}\text { Search } \\
\text { interval }\end{array}$ \\
\hline 1 & G1 & Length (m) & 0 & 46 & 9 & Soil depth (m) & 0.3 & 0.6 & 0.15 \\
\hline 3 & G2 & Length (m) & 0 & 200 & 15 & Soil depth (m) & 0.3 & 0.6 & 0.15 \\
\hline 5 & G3 & Length (m) & 0 & 211 & 11 & Soil depth (m) & 0.3 & 0.6 & 0.15 \\
\hline 6 & G4 & Length (m) & 0 & 180 & 9 & Soil depth (m) & 0.3 & 0.6 & 0.15 \\
\hline 8 & G5 & Length (m) & 0 & 46 & 9 & Soil depth (m) & 0.3 & 0.6 & 0.15 \\
\hline 9 & G6 & Length (m) & 0 & 46 & 9 & Soil depth (m) & 0.3 & 0.6 & 0.15 \\
\hline 10 & G8 & Length (m) & 0 & 34 & 3 & Soil depth (m) & 0.3 & 0.6 & 0.15 \\
\hline 11 & G7 & Length (m) & 0 & 30 & 6 & Soil depth (m) & 0.3 & 0.6 & 0.15 \\
\hline 12 & G9 & Length (m) & 0 & 21 & 11 & Soil depth (m) & 0.3 & 0.6 & 0.15 \\
\hline 18 & G10 & Length (m) & 0 & 30 & 6 & Soil depth (m) & 0.3 & 0.6 & 0.15 \\
\hline 2 & V1 & Length (m) & 0 & 213 & 15 & Soil depth (m) & 0.1 & 0.2 & 0.03 \\
\hline 4 & V2 & Length (m) & 0 & 91 & 6 & Soil depth (m) & 0.1 & 0.2 & 0.03 \\
\hline 7 & V3 & Length (m) & 0 & 180 & 9 & Soil depth (m) & 0.1 & 0.2 & 0.03 \\
\hline 14 & B1 & Length (m) & 0 & 80 & 15 & Soil depth (m) & 0.8 & 0.9 & 0.1 \\
\hline 15 & B2 & Length (m) & 0 & 91 & 15 & Soil depth (m) & 0.8 & 0.9 & 0.1 \\
\hline 16 & B3 & Length (m) & 0 & 91 & 15 & Soil depth (m) & 0.8 & 0.9 & 0.1 \\
\hline 21 & B4 & Length (m) & 0 & 150 & 15 & Soil depth (m) & 0.8 & 0.9 & 0.1 \\
\hline 20 & W1 & Length (m) & 0 & 910 & 91 & & & & \\
\hline 17 & P1 & Length (m) & 0 & 61 & 6 & & & & \\
\hline 22 & P2 & Length (m) & 0 & 61 & 15 & & & & \\
\hline
\end{tabular}

Table 3

Flow volume and pollutant loads under various scenarios.

\begin{tabular}{|c|c|c|c|c|c|c|c|}
\hline Scenarios & Cost $(\$)$ & Flow $\left(\mathrm{m}^{3} \mathrm{a}^{-1}\right)$ & $\mathrm{Zn}\left(\mathrm{kg} \mathrm{a}^{-1}\right)$ & $\mathrm{TN}\left(\mathrm{kg} \mathrm{a}^{-1}\right)$ & $\mathrm{TP}\left(\mathrm{kg} \mathrm{a}^{-1}\right)$ & $\operatorname{TSS}\left(\mathrm{kg} \mathrm{a}^{-1}\right)$ & $\operatorname{COD}\left(\mathrm{kg} \mathrm{a}^{-1}\right)$ \\
\hline PreDev & & 2575 & 0.12 & 32 & 0.45 & 137 & 113 \\
\hline PostDev & & 49,357 & 4.08 & 612 & 14.06 & 12,625 & 9674 \\
\hline Exsiting & & 28,622 & 1.81 & 277 & 6.35 & 4962 & 4038 \\
\hline Optimization option & $3,960,070$ & 18,271 & 0.91 & 156 & 2.72 & 2770 & 2321 \\
\hline Reduction/\% & & 36 & 43 & 44 & 55 & 44 & 43 \\
\hline
\end{tabular}

(1) Minimize cost for multiple control targets

Given multiple control targets, the scatter search optimization technique in SUSTAIN can be used to minimize the cost of pollutant removal. Considering that water quality (GB38382002), COD, TN and TP were selected as evaluation indices, the control targets were respectively set to $40 \%, 30 \%$, and $50 \%$ reductions of the value under the Existing scenario. A nearoptimal solution, with total cost of $\$ 3.96$ million and $43 \%, 44 \%$ and 55\% load reductions for COD, TN and TP, respectively, was identified after thousands of model runs. Flow volume and pollutant (TSS, Zn, TN, TP and COD) loads under various scenarios are listed in Table 3. A comparison of BMP sizes between those under the Existing scenario and those obtained through the optimization runs is presented in Table 4 . As indicated by this table, optimal BMP sizes are generally smaller than those under the Existing scenario. Other detailed modeling results of this solution were provided by SUSTAIN, including sizes of individual BMP for every sub-watershed.

(2) Cost-effectiveness curve for a single control target

To control a single pollutant, NSGA-II in SUSTAIN can be used to generate a cost-effectiveness curve for each pollutant. Flow volume and TSS were selected as evaluation factors in this run.

Table 4

Comparison between the existing scenario and the optimization scenario.

\begin{tabular}{llll}
\hline BMP & & Existing & $\begin{array}{l}\text { Optimization } \\
\text { option }\end{array}$ \\
\hline Green roof & Area $\left(\mathrm{m}^{2}\right)$ & 28,183 & 19,981 \\
& Soil depth $(\mathrm{m})$ & 0.61 & 0.46 \\
Wet pond & Area $\left(\mathrm{m}^{2}\right)$ & 3716 & 2787 \\
Vegetated swale & Area $\left(\mathrm{m}^{2}\right)$ & 74 & 52 \\
\multirow{2}{*}{ Porous pavement } & Soil depth $(\mathrm{m})$ & 0.15 & 0.12 \\
Bioretention & Area $\left(\mathrm{m}^{2}\right)$ & 10,441 & 4376 \\
& Area $\left(\mathrm{m}^{2}\right)$ & 1672 & 1078 \\
& Soil depth $(\mathrm{m})$ & 0.91 & 0.76 \\
\hline
\end{tabular}

The optimization engine performs iterative searches to identify cost-effective solutions. After thousands of optimization runs, two cost-effectiveness curves based on the annual flow volume and TSS load reductions were developed (Fig. 7). Each curve represents the optimal combinations of BMP that collectively remove the targeted amounts of flow volume and TSS load at the least cost. The $x$-axis denotes the construction cost and $y$-axis the annual average flow volume and pollutant load reduction percentage of the value under the Existing scenario. Each data point in the figure represents the removal effectiveness and corresponding cost of each BMP scenario. It is seen that any solutions inside the curve are inferior; i.e., there is a better solution that either provides more pollutant reduction benefit at the same cost, or less cost while providing the same benefits.

With different solutions, the annual flow volume and TSS load reductions were in the ranges $0-43 \%$ and $0-48 \%$, respectively

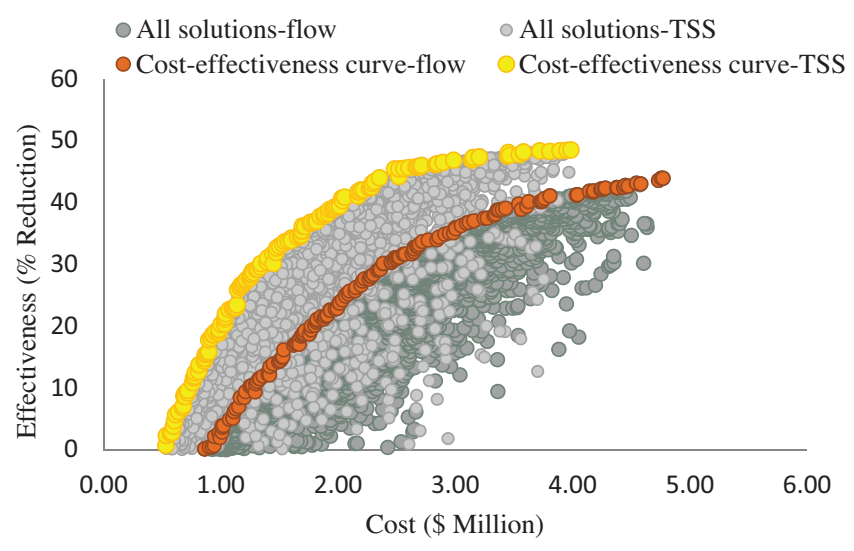

Fig. 7. Cost-effectiveness curves for flow and TSS. 


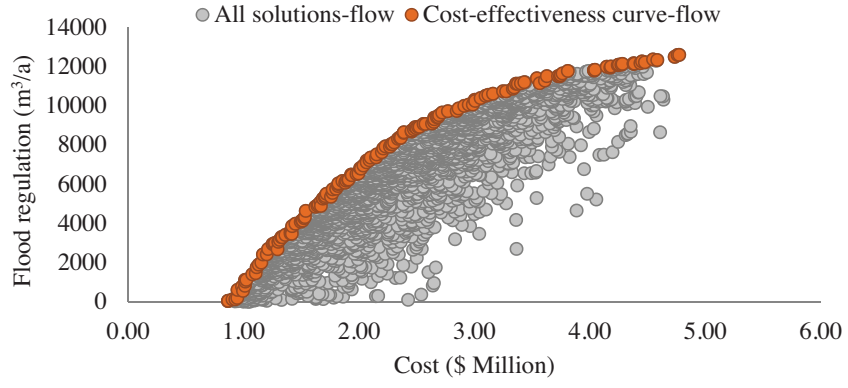

Fig. 8. Flood regulation under various costs.

(Fig. 7). The cost-effectiveness curves show that TSS load reduction was higher than flow volume reduction, based on the same cost. This difference is because TSS load reduction is a combined effect of the flow volume reduction and pollutant controls via the BMP. If the target is set to $30 \%$ reduction of annual flow volume at the study site, the least-cost option for BMP costs $\$ 1.34$ million. This option achieved a cost savings of $\$ 0.12$ million compared to that under the Existing scenario. If the target is set to 30\% reduction of TSS at the study site, the least-cost option for BMP implementation is $\$ 2.38$ million. Detailed modeling results of each scenario were also provided by SUSTAIN, including sizes of individual BMP for every sub-watershed.

\subsection{Ecosystem services}

After transformation of green and water spaces by BMP implementation, ecosystem services provided by green and water spaces were improved, and quantities were further increased by optimization. Figs. 8 and 9 show ecosystem service quantities for flood regulation and pollutant purification under various BMP solutions following optimization. The $\mathrm{x}$-axis denotes construction cost and the $y$-axis the increment of ecosystem service quantities under the Existing scenario. In particular, Fig. 8 shows the flood mitigation increment and corresponding cost; flood mitigation was calculated based on annual flow volume. Fig. 9 shows the pollutant purification increment and corresponding cost. TSS was selected as the assessment pollutant, for which annual load was used for calculation of pollutant purification. The highlighted curves present given ecosystem services increment targets at minimum cost.

\section{Discussion}

BMP is capable of mitigating flood and stormwater pollution caused by urban runoff. SUSTAIN supports analysis and decisionmaking for stormwater management planning. In this study, to meet the discharge standard, the minimum cost was $\$ 3,960,070$ with $\$ 297,749$ per hectare at the study site. Compared with the

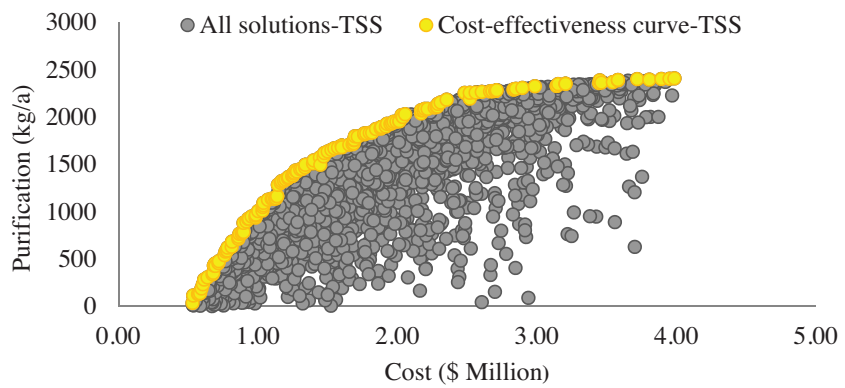

Fig. 9. TSS purification under various costs.
Peace Cross site, the cost was $\$ 168,667$ per hectare (Cheng et al., 2009). This result indicates that total flow volume and pollutant loads generated at the study site were greater than those at the Peace Cross site. Therefore, larger BMP sizes would need to be implemented to mitigate water quantity and quality effects. SUSTAIN provided data of BMP cost distribution versus flow volume and pollutant reduction effectiveness via the cost-effectiveness curve. With the goal of $36 \%$ reduction in flow volume, green roofs accounted for $93 \%$ of total BMP costs, whereas the cost for bioretention was 0 . This result implies that green roofs were an optimal option to achieve the $36 \%$ reduction goal, but that bioretention was not.

In the present study, the reductions of flow volume and pollutants should be set to least 63\% compared to those under the PostDev scenario. However, a single BMP technology (such as bioretention or green roof) discharge would require further treatment (Chen et al., 2013; Czemiel Berndtsson, 2010; Elizabeth, 2012; Deletic and Fletcher, 2006). Therefore, it was very important in the present study to carefully select and combine BMP to meet water quality standards according to the literature.

We did no calibration of flow modeling, because there were no monitoring data available for the site. In future studies, calibration should be done using monitoring data.

Literature on the valuation of ecosystem services has increased considerably in recent years (Chen et al., 2009; Jenkins et al., 2010; Tallis and Polasky, 2009; Tong et al., 2007). However, little work has been done to quantify these services, which poses a major challenge to their research application to actual land management and economic and policy decisions. We used SUSTAIN model output to quantify ecosystem functions related to two ecosystem services, flood regulation and pollutant purification. The results show that these two services increased significantly after planning the green and water spaces. The results are sensitive to hydrologic and water quality parameters. Here, the monitoring data were used in the model as water quality parameters, which could cause uncertainties with use for an entire year. Therefore, more monitoring data of runoff quality would be useful in future study. We confined our study to two types of ecosystem services. Future improvements are needed to explore other ecosystem service quantities, such as cultural, spiritual, and recreational services.

Ecosystem services were quantified by output of the SUSTAIN model. Recently, tools to assess ecosystem services have been developed at various spatial scales (Nelson and Daily, 2010; Posthumus et al., 2010). Integrated Valuation of Ecosystem Services and Tradeoffs (InVEST) was developed for the country-to-state level (Daily et al., 2009; Tallis and Polasky, 2009). The Soil and Water Assessment Tool (SWAT) has been applied to watershed, sub-basin and hydrologic response unit scales (Arnold and Fohrer, 2005; Logsdon and Chaubey, 2013). However, few models have been developed for site scale. The SUSTAIN model has the capability to simulate site scale processes in mixed land use conditions, and could be used to calculate ecosystem services at other spatial scales (e.g., regional and watershed). For ease of comparison, although all ecosystem service quantities in the present study were calculated at annual scale, SUSTAIN can simulate at daily, monthly and single storm event scales. Traditional ecosystem service tools estimate those services (e.g., flood regulation, nutrient filtration, water supply) (Vigerstol and Aukema, 2011) by simplifying hydrologic processes. SUSTAIN can more accurately estimate ecosystem service quantities, based on hydrologic, hydraulic, and water quality modeling.

\section{Conclusions}

We proposed a set of BMP to reduce runoff and pollutant load. A factory in Ma'anshan was selected as a case study for analyzing 
the benefits of BMP in reducing runoff volume and pollutant load. The results indicate that compared with the developed condition, the BMP plan would reduce total runoff volume, TSS, Zn, TN, TP and COD loads by $41 \%, 62 \%, 55 \%, 57 \%, 55 \%$ and $60 \%$, respectively. BMP sizes could be further adjusted using the optimization module of SUSTAIN. Considering the receiving water quality, the minimum cost was $\$ 3,960,070$ when the COD, TN and TP control targets were respectively reduced by $40 \%, 30 \%$ and $50 \%$ of the value under the Existing scenario. In this manner, decision makers can identify the most cost-effective BMP plan, given a control target or fixed cost. This research result is of practical importance for urban nonpoint source pollution caused by industrial activities.

\section{Acknowledgements}

This research was financially supported by the National Natural Science Foundation of China (General Program, No. 71273254). We also express our gratitude to the reviewers and editors for their comments on the manuscript.

\section{References}

Abu-Zreig, M., Rudra, R.P., Lalonde, M.N., Whiteley, H.R., Kaushik, N.K., 2004. Experimental investigation of runoff reduction and sediment removal by vegetated filter strips. Hydrol. Process. 18, 2029-2037.

Arcy, B.D., Frost, A., 2001. The role of best management practices in alleviating. Sci. Total Environ. 265, 359-367.

Arnold, J.G., Fohrer, N., 2005. SWAT2000: current capabilities and research opportunities in applied watershed modelling. Hydrol. Process. 19, 563-572.

Arnold, J.G., Srinivasan, R., Muttiah, R.S., Williams, J.R., 1998. Large area hydrologic modeling and assessment - Part I: Model development. J. Am. Water Resour. Assoc. 34, 73-89.

Ballo, S., Liu, M., Hou, L., Chang, J., 2009. Pollutants in stormwater runoff in Shanghai (China): implications for management of urban runoff pollution. Prog. Nat. Sci. 19, 873-880.

Brown, J.N., Peake, B.M., 2006. Sources of heavy metals and polycyclic aromatic hydrocarbons in urban stormwater runoff. Sci. Total Environ. 359, $145-155$.

Che, W., Liu, Y., Li, J.Q., 2003. Quality of urban rainwater and pollution control home and broad. Water Wastewater Eng. 29, 38-42.

Chen, X., Peltier, E., Sturm, B.S., Young, C.B., 2013. Nitrogen removal and nitrifying and denitrifying bacteria quantification in a stormwater bioretention system. Water Res. 47, 1691-1700.

Chen, Z.M., Chen, G.Q., Chen, B., Zhou, J.B., Yang, Z.F., Zhou, Y., 2009. Net ecosystem services value of wetland: environmental economic account. Commun. Nonlinear Sci. Numer. Simul. 14, 2837-2843.

Cheng, M.-S., Zhen, J.X., Shoemaker, L., 2009. BMP decision support system for evaluating stormwater management alternatives. Front. Environ. Sci. Eng. China 3, 453-463.

Clark, S.E., WRE, P.E.D., Steele, K.A., Spicher, J., Siu, C.Y.S., Lalor, M.M., Pitt, R., WRE, P.E.D., Kirby, J.T., 2008. Roofing materials' contributions to storm-water runoff pollution. J. Irrig. Drain. Eng. 134, 638-644.

Coombes, P.J., Argue, J.R., Kuczera, G., 1999. Figtree Place: a case study in water sensitive urban development. Urban Water 1, 335-343.

Czemiel Berndtsson, J., 2010. Green roof performance towards management of runoff water quantity and quality: a review. Ecol. Eng. 36, 351-360.

Daily, G.C., Polasky, S., Goldstein, J., Kareiva, P.M., Mooney, H.A., Pejchar, L., Ricketts, T.H., Salzman, J., Shallenberger, R., 2009. Ecosystem services in decision making: time to deliver. Front. Ecol. Environ. 7, 21-28.

Davis, B.S., Birch, G.F., 2009. Catchment-wide assessment of the cost-effectiveness of stormwater remediation measures in urban areas. Environ. Sci. Policy 12, 84-91.

Deletic, A., Fletcher, T.D., 2006. Performance of grass filters used for stormwater treatment-a field and modelling study. J. Hydrol. 317, 261-275.

Elizabeth, F., 2012. Stormwater BMP treatment performance variability for sediment and heavy metals. Sep. Purif. Technol. 84, 95-103.

EPA, 1999. Preliminary Data Summary of Urban Stormwater Best Management Practices. Office of Water, Washington, DC.

EPA, 2009. SUSTAIN - A Framework for Placement of Best Management Practices in Urban Watersheds to Protect Water Ouality. EPA/600/R-09/095. Office of Research and Development, Cincinnati, OH http://www.epa.gov/nrmrl/pubs/ 600r05040/600r05040.pdf

Goonetilleke, A., Egodawatta, P., Kitchen, B., 2009. Evaluation of pollutant build-up and wash-off from selected land uses at the Port of Brisbane, Australia. Mar. Pollut. Bull. 58, 213-221.
Gromaire-Mertz, M.C., Garnaud, S., Gonzalez, A.C.G., 1999. Characterisation of urban runoff pollution in Paris. Water Sci. Technol. 39, 1-8.

Hossain, I., Imteaz, M.A., Hossain, M.I., 2011. Application of build-up and wash-off models for an east-Australian catchment. Int. J. Environ. Sci. Technol. Eng. Res. 5.

Jenkins, W.A., Murray, B.C., Kramer, R.A., Faulkner, S.P., 2010. Valuing ecosystem services from wetlands restoration in the Mississippi Alluvial Valley. Ecol. Econ. 69, 1051-1061.

Jia, H., Lu, Y., Yu, S.L., Chen, Y., 2012. Planning of LID-BMPs for urban runoff control: the case of Beijing Olympic Village. Sep. Purif. Technol. 84, 112-119.

Kim, L.H., Zoh, K.D., Jeong, S., Kayhanian, M., Stenstrom, M.K., ASCE, F., 2006. Estimating pollutant mass accumulation on highways during dry periods. J. Environ. Eng. 132, 985-993.

Kim, M.H., Sung, C.Y., Li, M.-H., Chu, K.-H., 2012. Bioretention for stormwater quality improvement in Texas: removal effectiveness of Escherichia coli. Sep. Purif. Technol. 84, 120-124.

Lee, J.G., Selvakumar, A., Alvi, K., Riverson, J., Zhen, J.X., Shoemaker, L., Lai, F.-H., 2012. A watershed-scale design optimization model for stormwater best management practices. Environ. Model. Software 37, 6-18.

Lee, J.H., Bang, K.W., 2000. Characterization of urban stormwater. Water Res. 34 1773-1780.

Lee, J.H., BANG, K.W., Ketchum, L.H., Choe, J.S., Yu, M.J., 2002. First flush analysis of urban storm runoff. Sci. Total Environ. 293, 163-175.

Li, L.Q., Yin, C.Q., He, Q.C., Kong, L.L., 2007. First flush of storm runoff pollution from an urban catchment in China. J. Environ. Sci. 19, 295-299.

Logsdon, R.A., Chaubey, I., 2013. A quantitative approach to evaluating ecosystem services. Ecol. Model. 257, 57-65.

Luo, H.B., Li, M., Xu, R., Fu, X.Y., Huang, G., Huang, X.X., 2012. Pollution characteristics of urban surface runoff in a street community. Sustain. Environ. Res. 22 61-68.

Napier, F., Jefferies, C., Heal, K.V., Fogg, P., Arcy, B.J., Clarke, R., 2009. Evidence of traffic-related pollutant control in soil-based sustainable urban drainage systems (SUDS). Water Sci. Technol., 60

Nelson, E.J., Daily, G.C., 2010. Modelling ecosystem services in terrestrial systems. F1000 Biol. Rep. 2, 1-6.

Niemelä, J., Saarela, S.-R., Söderman, T., Kopperoinen, L., Yli-Pelkonen, V., Väre, S., Kotze, D.J., 2010. Using the ecosystem services approach for better planning and conservation of urban green spaces: a Finland case study. Biodivers. Conserv. 19, 3225-3243.

Oraei Zare, S., Saghafian, B., Shamsai, A., 2012. Multi-objective optimization for combined quality-quantity urban runoff control. Hydrol. Earth Syst. Sci. 16 4531-4542.

Perez-Pedini, C., Limbrunner, J.F., Vogel, R.M., 2005. Optimal location of infiltrationbased best management practices for storm water management. J. Water Resour. Plan. Manage. 131, 441-448.

Posthumus, H., Rouquette, J.R., Morris, J., Gowing, D.J.G., Hess, T.M., 2010. A framework for the assessment of ecosystem goods and services; a case study on lowland floodplains in England. Ecol. Econ. 69, 1510-1523.

Ren, Y.F., Wang, X.K., Ouang, Z.Y., Zheng, H., 2008. Stormwater runoff quality from different surfaces in an urban catchment in Beijing, China. Water Environ. Res. 80, 719-724.

Scholz, M., Grabowiecki, P., 2007. Review of permeable pavement systems. Build Environ 42, 3830-3836.

Soulis, K.X., Valiantzas, J.D., 2011. SCS-CN parameter determination using rainfallrunoff data in heterogeneous watersheds. The two-CN system approach. Hydrol. Earth Syst. Sci. Discuss. 8, 8963-9004.

Soulis, K.X., Valiantzas, J.D., 2012. Identification of the SCS-CN parameter spatial distribution using rainfall-runoff data in heterogeneous watersheds. Water Resour. Manage. 27, 1737-1749.

Tallis, H., Polasky, S., 2009. Mapping and valuing ecosystem services as an approach for conservation and natural-resource management. Ann. N. Y. Acad. Sci. 1162, 265-283.

Tong, C., Feagin, R.A., Lu, J., Zhang, X., Zhu, X., Wang, W., He, W., 2007. Ecosystem service values and restoration in the urban Sanyang wetland of Wenzhou, China. Ecol. Eng. 29, 249-258.

Vigerstol, K.L., Aukema, J.E., 2011. A comparison of tools for modeling freshwater ecosystem services. J. Environ. Manage. 92, 2403-2409.

Vijayaraghavan, K., Joshi, U.M., Balasubramanian, R., 2012. A field study to evaluate runoff quality from green roofs. Water Res. 46, 1337-1345

Wang, B., Li, T., 2009. Buildup characteristics of roof pollutants in the Shanghai urban area, China. J. Zhejiang Univ. Sci. A 10, 1374-1382.

Wang, S., He, Q., Ai, H., Wang, Z., Zhang, Q., 2013. Pollutant concentrations and pollution loads in stormwater runoff from different land uses in Chongqing. J. Environ. Sci. 25, 502-510.

Zhang, G., 2006. Multiobjective optimization of low impact development scenarios in an urbanizing watershed. In: Proceedings of the AWRA Annual Conference, Baltimore, USA, pp. 1-7.

Zhen, X., Yu, S., Lin, J., 2004. Optimal location and sizing of stormwater basins at watershed scale. J. Water Resour. Plan. Manage. 130, 339-347. 